\title{
Analysis of tectonic activity of the North Anatolian Fault based on SBInSAR method
}

\author{
Karolina Owczarz ${ }^{1, *}$ \\ ${ }^{1}$ Wrocław University of Science and Technology, Faculty of Geoengineering, Mining and Geology, 27 Wyb. Wyspiańskiego St., \\ 50-370 Wrocław, Poland
}

\begin{abstract}
The North Anatolian Fault situated in Turkey is one of the longest and most active tectonic faults in the world. The paper presents an analysis of tectonic activity in its area based on the method of Small Baseline Synthetic Aperture Radar Interferometry. For this purpose 73 satellite SAR images and specialized software GMT5SAR were used with implement the SBAS algorithm. In addition, the most important aspects of data processing and their final products were presented, which determined the surface displacements occurring in the surveyed area from 1 January 2014 to 1 March 2017. The displacements of the SBAS surface area ranged from $-10 \mathrm{~cm}$ to $+10 \mathrm{~cm}$. Based on the obtained results and their analysis, the author also assessed the suitability of SBInSAR technology for areas of land displacement.
\end{abstract}

\section{Introduction}

The tectonic activity of the terrain is related to the geological structure of the Earth, as well as to the endogenous processes, which have great influence on the topography. The theory of lithosphere tectonics developed in the early 1960s by Harry Hammond Hess assumes that the lithosphere consists of smaller and larger plates forming the continental crust and the oceanic crust. Under the lithosphere, there is an asthenosphere or layer of the upper part of the Earth's mantle, characterized by high plasticity and reduced velocity of seismic wave propagation. The plastic properties of the asthenosphere allow the movement of lithosphere plates and isostatic movements. In the asthenosphere, there are convection currents responsible for the wandering of magma in the interior of the Earth. Lithospheric plates move and are accompanied by pressure or lateral stresses, which cause the formation of new, tectonic forms of the relief, such as: mountains, volcanoes, faults, oceanic trenches, etc. The geomorphology research new landforms, determines their shape, geometric features, provenance, mechanism of development and age. To determine the tectonic activity within terrain forms measurements: geodetic (leveling, tachymetry, laser scanning, GNSS), seismic, geophysical or remote sensing are made.

Technique Small Baseline Synthetic Aperture Radar Interferometry (SBInSAR) also called Small Baseline Subset (SBAS) is one of many remote sensing methods the satellite radar interferometry. SBInSAR method examines small, to long-term land displacements, for example: tectonic faults, slides, volcanoes, water reservoirs, glaciers, building objects, subsidences or uplifts terrain, mining and post mining area, etc. SBAS is derivative of Differentiall Synthetic Aperture Radar Interferometry and allow to detection slow movements at the milimeter level by difference between the main interferogram and the synthesized interferogram. Currently SBAS makes to the latest algorithm used to monitoring surface displacement, which generates multiple pairs of interferograms with small spatial and temporal baseline. This minimizes the effects spatial and temporal decorrelation and topographic artifacts due to the use of Digital Elevation Model (DEM). A detailed description of the SBInSAR method was presented in publications $[1,2]$.

The use of satellite images to determine the topography of the Earth and the physical processes that occur on it are of great interest, as evidenced by numerous scientific publications on this subject $[3,4]$. A study of the interactions between permafrost and infrastructure along the Qinghai-Tibet Railway was presented in article [5]. Based over a dozen images and application of the SBAS method, they analyzed the relationship between surface displacement, permafrost active layer and environmental conditions. In this project, the researchers estimated that surface motions along embankment are in the range of $20 \mathrm{~mm} / \mathrm{yr}$ to $+20 \mathrm{~mm} / \mathrm{yr}$. The issue of monitoring land subsidence and fault displacement occurring on the Datong Basin (China) has appeared in the publication [6]. For the SBInSAR calculation 40 radar scenes were used and were taken the relationships among the regional land subsidence, ground fissures and faults activity: Kouquan, Liulengshan Premont and Hengshan Premont. As a result of the displacement studies conducted in the Datong Basin, the variation range $-15.5 \mathrm{~mm} / \mathrm{yr}$ to $+10.4 \mathrm{~mm} / \mathrm{yr}$. The SBAS method was also used to detect and monitor subsidence of land in the Nordic countries [7]. During

Corresponding author: karolina.owczarz@pwr.edu.pl 
the research, the results of settlements at the level of 5 $\mathrm{mm} /$ year were used. It turns out that SBInSAR is not only an appropriate tool for detecting displacements, but also for assessing urban policy and supporting the design and implementation of effective development strategies [8].

This article focuses on the determining surface displacement in the North Anatolian Fault Zone (NAFZ) from 1 January 2014 to 1 March 2017 by acquiring satellite images, using SBInSAR technique and developing results.

\section{Study area - North Anatolian Fault}

The North Anatolian Fault (NAF) is located in the northern part of Turkey and extends from the east to the west of the country (Fig. 1). This is one of the longest tectonic faults in the world. It was first described in the late 1940s by I. Ketin [9] and is one of the most well studied zones of tectonic activity [10-12]. NAF is a particularly dangerous geological formation that has caused massive damage in the Marmara Sea region.

There are numerous earthquakes documented over the centuries, and the 1999 Izmite disaster has led geologists to discover that the North Anatolian Fault are numerous smaller faults that create a dynamically connected tectonic form of a single $1,600 \mathrm{~km}$ long fault. Thus, whenever there are strong tremors in the region, their energy is transferred along the rock fissures to other areas [14].

NAFZ is an intra-continental, strike-slip, transform fault that forms the geological boundary between the Anatolian plate and Eurasian plate. Its right-lateral slip is clearly due to physiographic conditions and geological features. The fault creates a narrow fissure running parallel to the Black Sea coast, starting from the Karliova triple junction in the east, to the town of Geyve in the west, where it divides into three sections in the eastern part of the Marmara Sea. These three bands stretch west to the bays: Saros and Edremit, with the northern section running through the Gulf of Izmit [10].

The origin of the NAF is controversial, although the most probable theory is that it originated as a result of the partial closure of the southern part of the Tethys Ocean along sector between present-day Bitlis town in eastern Turkey and the Zagros mountains extending east of Iran during the middle Miocene. The fault formed earlier in the zone of closure of the northern part of the prehistoric ocean between Paleocene and Eocene. The structure of the NAF was formed shortly after the continental collision between the Arabic plate and the Eurasian in eastern Anatolia [11]. Due to the above events, the fault has so far been characterized by a varied geological structure on both sides of the formation.

Due to the length of the NAF was exposed only the fragment between $32^{\circ}$ and $33^{\circ}$ east longitude (Fig. 2). According to the division of NAF proposed in the publication [12] this fragment belongs to the central part of the structure in the area, where in the XX century there were several earthquakes of magnitude over 7 .

Therefore, the project was limited to only fragment of the area along the NAF, covered by swath no. 3, to verify the suitability of the SBAS method for analyzing tectonic activity and to obtain the values of displacement occurring in the area under investigation.

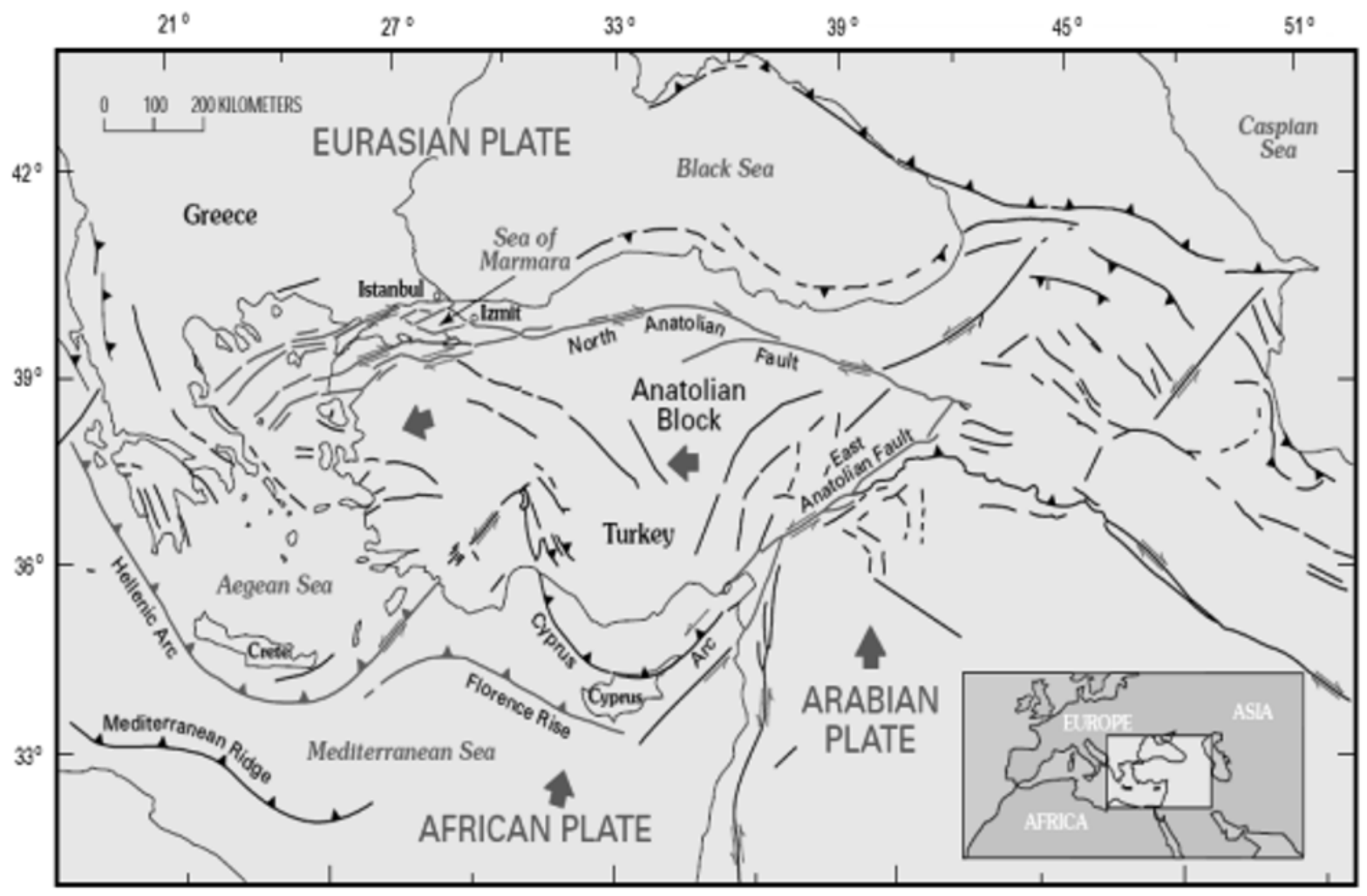

Fig. 1. Geological map of Turkey [13]. 


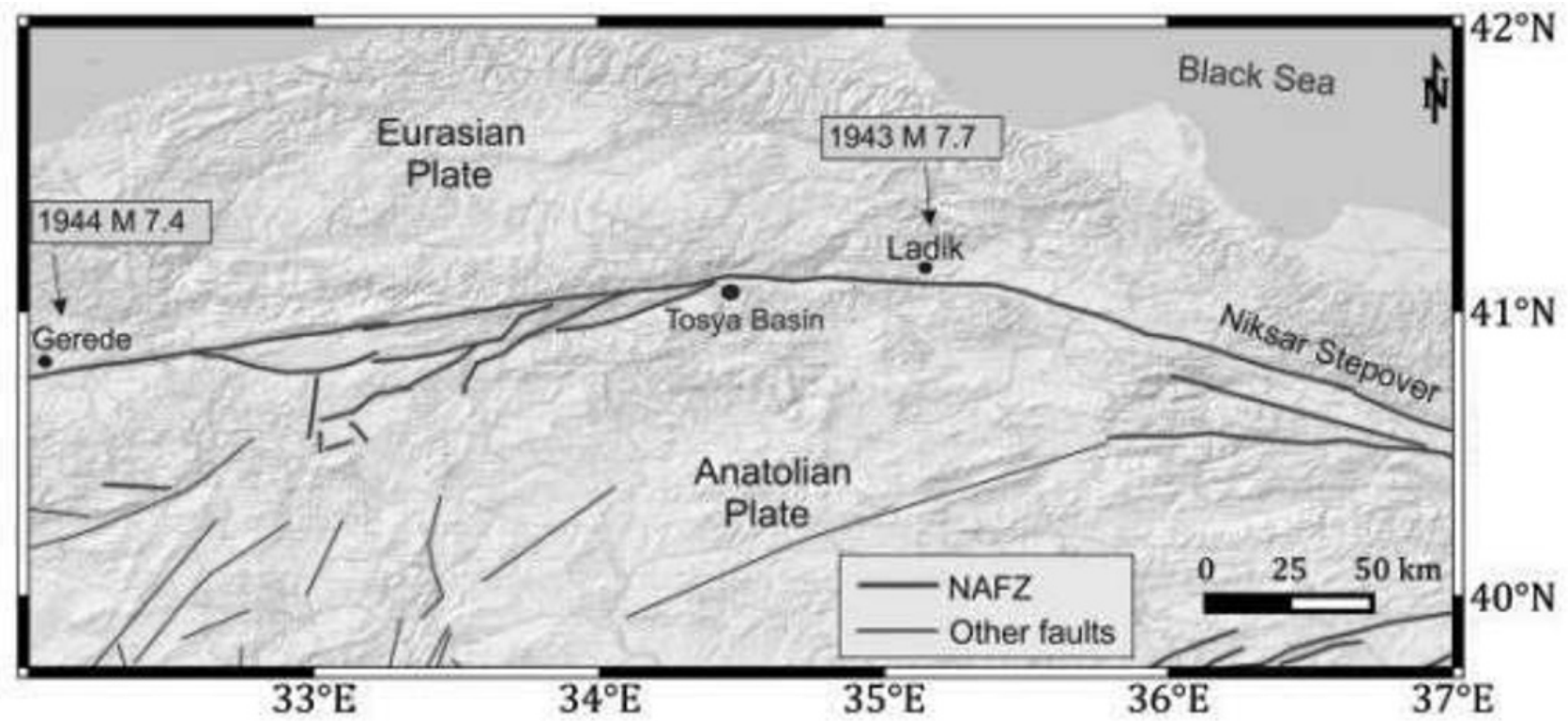

Fig. 2. Map of the central part of the NAFZ [12].

\section{SAR data collections of the NAF}

The project uses satellite data registered by the Sentinel$1 \mathrm{~A}$ and Sentinel-1B satellites, assume of the Copernicus program under the European Space Agency's in the period from 1 January 2014 to 1 March 2017. In addition to satellite images, in SBAS technique was required to obtain a Digital Elevation Model and precise satellite ephemeris. Radar images consisted of 73 scenes (Figs. 3, $4 \mathrm{~A}$ ) including 60 from Sentinel-1A and 13 from Sentinel-1B and were characterized by following parameters: ascending/descending, Single Look Complex (SLC), Relative Orbit Number (167) and VV polarization.

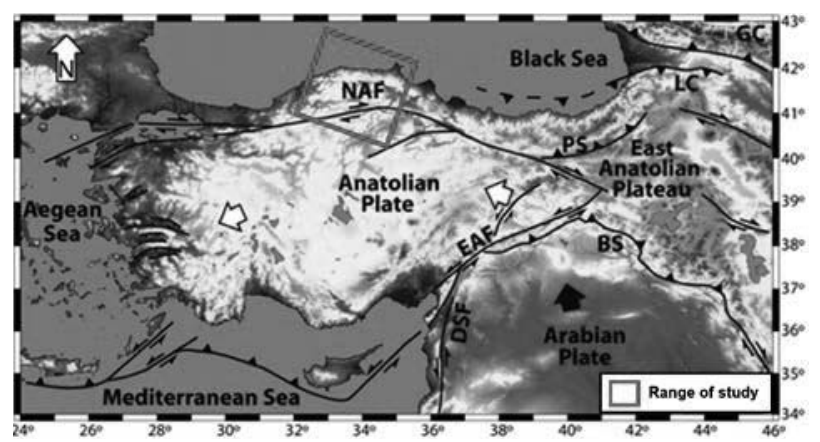

Fig. 3. Range of downloaded satellite images [15].

Also was used the DTM (Fig. 4B) of the Shuttle Radar Topography Mission (SRTM) with a resolution of approximately 1 " (30 meters) as a script. The Digital Elevation Model was reduced to a synthesized interferogram eliminating the components responsible for topography [16]. The last group of necessary data was information on the precise position of the satellites, because in particular in the case of interferometry, the Sentinel-1 requires meticulous control.
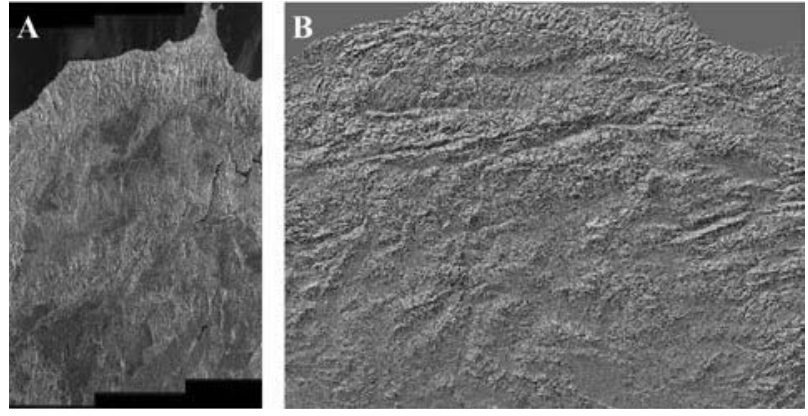

Fig. 4. A) The satellite image [17], B) Digital Elevation Model [18].

The above data came from the following web portals: Copernicus Open Access Hub - satellite images, GMTSAR - DTM as a script and Sentinel-1 PDGS precise position of the satellites providing complete, free and open user access to the products. The most important element was the proper preparation of data by organizing them in such a way that they could be processed in batch files.

\section{SBAS data processing}

The SBInSAR is a DInSAR algorithm for detecting displacement of the Earth's surface and analyzing its time evolution by generating average velocity maps and time series of displacements in direction line of sight LOS [19]. In particular, the method consists in the creation of interferograms by the appropriate choice of SAR data pairs characterized by small time thresholds and small spatial baselines [2]. This is to mitigate the effects of signal decorrelation, and thus maximize the number of coherent pixels in terms of time. SBAS allows limiting the impact of topographical artifacts and includes filtering elements of atmospheric phases based on the observation of their signal, which is strongly correlated in outer space but less in time [1]. 
The SBAS method was described in detail in publication of [1], in which the entire calculation scheme is presented mathematically. The following is a brief description of the individual implementation processes of the Casu [20] SBAS algorithm:

Stage 1: Evaluation of the orbital parameters associated to each SAR acquisition (subsequently used within the estimation of the spatial baseline value) and reference Master image selection.

Stage 2: Generation of a set of single look SAR images (SLC) from the available raw data files (focusing).

Stage 3: DEM conversion into reference Master image SAR coordinates and computation of sensor to target distance files (range files) for each acquisition.

Stage 4: Optimal interferometric data pair distribution selection.

Stage 5: Co-registration of each SLC data pair with respect to the selected reference Master image.

Stage 6: Differential interferograms and corresponding spatial coherence maps generation.

Stage 7: Noise-filtering of the generated DInSAR fringes.

Stage 8: Generation of the mean displacement velocity map and the corresponding time series, for each coherent pixel of the investigated area, via the inversion of the computed sequence of DInSAR interferograms. At the same time, an estimate of the possible residual topographic components and the atmospheric contributions is also accomplished;

Stage 9: Geocoding of the obtained results and projection into a universal cartographic grid.

All calculations were done in the GMT5SAR software, where was made the so-called batch processing that is the automatic processing of large SAR data volumes to generate interferograms (Fig. 5).

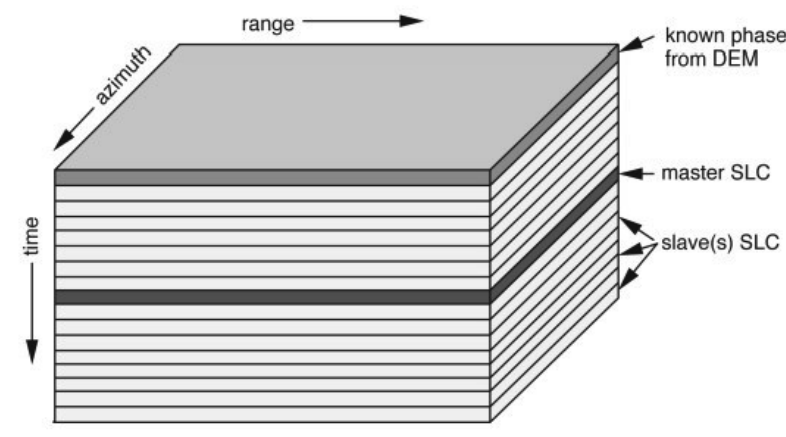

Fig. 5. Batch processing for time series [21].

The entire processing was implemented in accordance with the individual stages highlighted in the SBAS method and with appropriately selected input parameters for the studied area. Due to the large number of satellite imaging, more than 400 interferograms representing the phase difference between two radar scenes were obtained. The most important stage was the development of the phase consisting in completing the measured phase by a multiple of $2 \pi$, to then proceed with the calculation of cumulative displacements.

\section{Analysis of results}

Turkey is a seismically active area as evidenced by the scientific articles $[22,23]$. This activity is due to the fact that Turkey is located at the junction of several lithosphere plates (Eurasian plate, African plate, Arabic plate and Iranian plate). The central part of the fault compared to the eastern and western parts exhibits much less seismic shocks [12]. As a result of the SBAS algorithm, 73 maps cumulative displacements between successive satellite data acquisition were obtained. The article was presented selected ones at several monthly intervals between the first and the last image (Fig. 6). The maps below do not have a fixed time interval. Only maps that show significant displacement are selected.

On this basis, the tectonic activity of the examined area was analyzed. In addition, four points A, B, C and $\mathrm{D}$ were applied to check their individual displacements. Points A and B were located at the beginning and end of the analyzed fault segment. Points $\mathrm{C}$ and $\mathrm{D}$ were placed respectively north and south of the fault zone to see if the changes occurring in the fault strongly affect the surrounding area. The following displacement maps refer to two data groups (three maps for each set) created during the calculation.

By analyzing the cumulative displacements comparison, it is clear that the variations in the surveyed area range from $-10 \mathrm{~cm} / \mathrm{yr}$ to $+10 \mathrm{~cm} / \mathrm{yr}$, with SBAS accuracy being able to reach millimeters [24]. The dominant part is the uplifts (green and yellow hues), while there are few settlements of the surface (blue hues). Displacements occur at the points of the fault line. Below is a chart of cumulative time displacements for four selected points (Fig. 7): A, B, C and D, which were analyzed. The points were placed in such space of the study area that it was possible to determine the variability of the changes. Thus, the largest displacements from $-1.4 \mathrm{~cm}$ to $+2.3 \mathrm{~cm}$ show the B point located in the eastern part of the area, where the branching is visible on several new fault lines. Likewise, the situation for point $\mathrm{C}$ is placed in the north, whose values oscillate range from $-1.5 \mathrm{~cm}$ to $+1.5 \mathrm{~cm}$. Point $\mathrm{A}$, despite being located in the western fragment of the fault line, is characterized by quite small displacements from the level of $+0.4 \mathrm{~cm}$ to $+1.5 \mathrm{~cm}$. On the other hand, point $\mathrm{D}$ of all shows the smallest changes during the entire observation period, since they fall within the range of $-0.2 \mathrm{~cm}$ to $+0.6 \mathrm{~cm}$. Analyzing the points in pairs A-D and $\mathrm{B}-\mathrm{C}$ results the dependence characterizing the course of displacements in the examined period. Namely, the displacements of points $\mathrm{A}$ and $\mathrm{D}$ tend to increase. However, this point A reaches higher values. In the case of the B-C graph, there are significant changes in time, as the displacements from the smallest negative values pass into the highest positive values. This state occurs up to the half of the analyzed period, while later the displacement gradually increases. Point $\mathrm{B}$ is characterized by greater displacements from point C. 


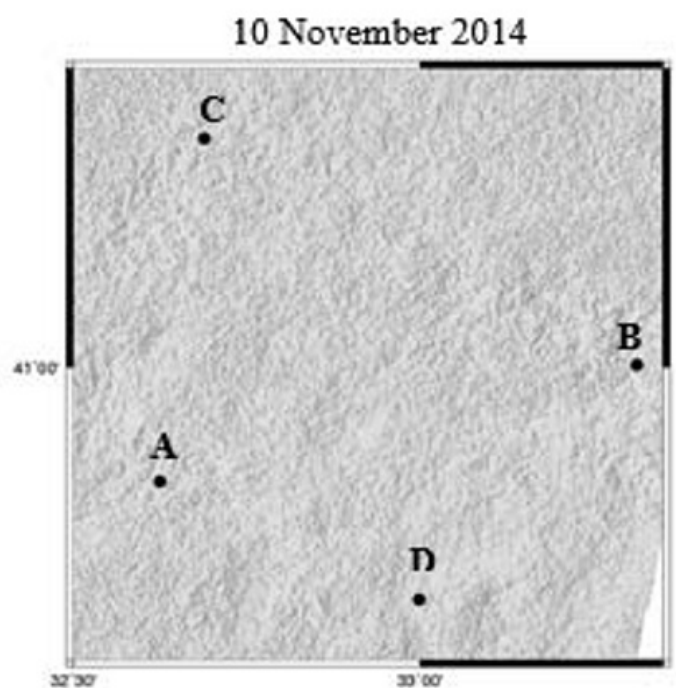

8 June 2016

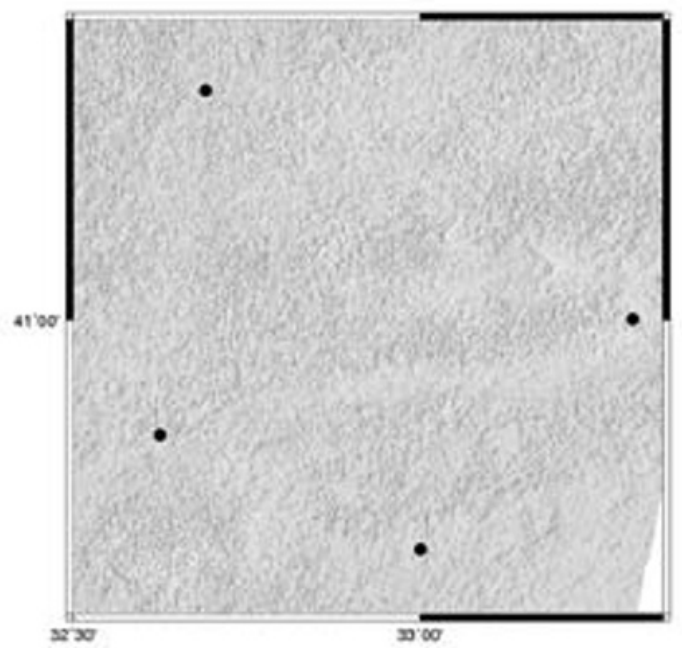

11 December 2016

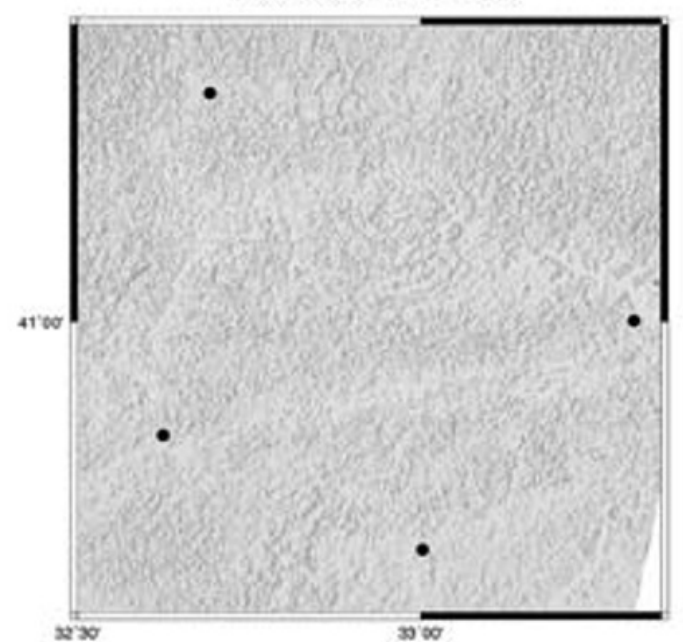

18 September 2015

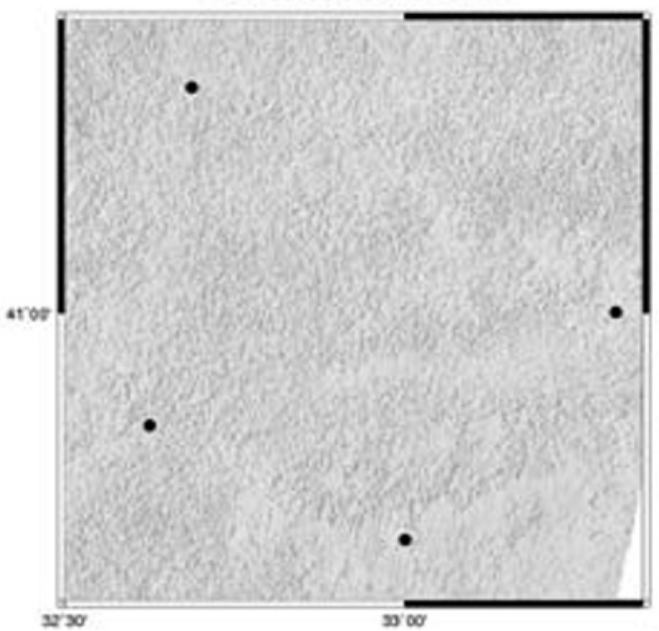

7 August 2016

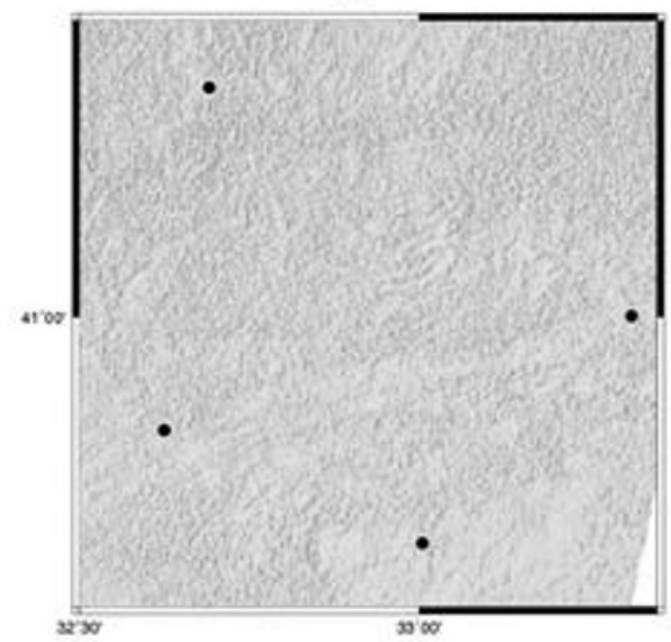

27 February 2017

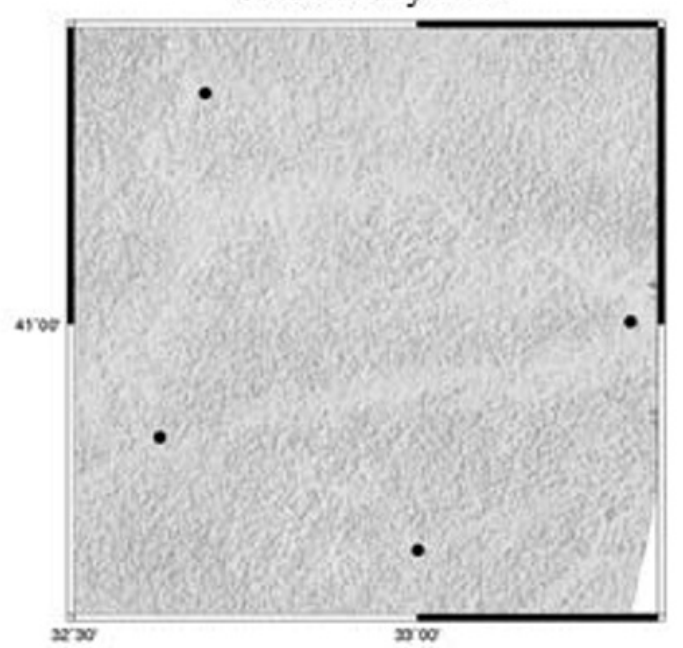

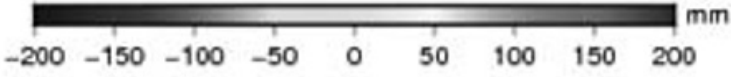

Fig. 6. Cumulative displacement in region the NAFZ from November 2014 to February 2017. 


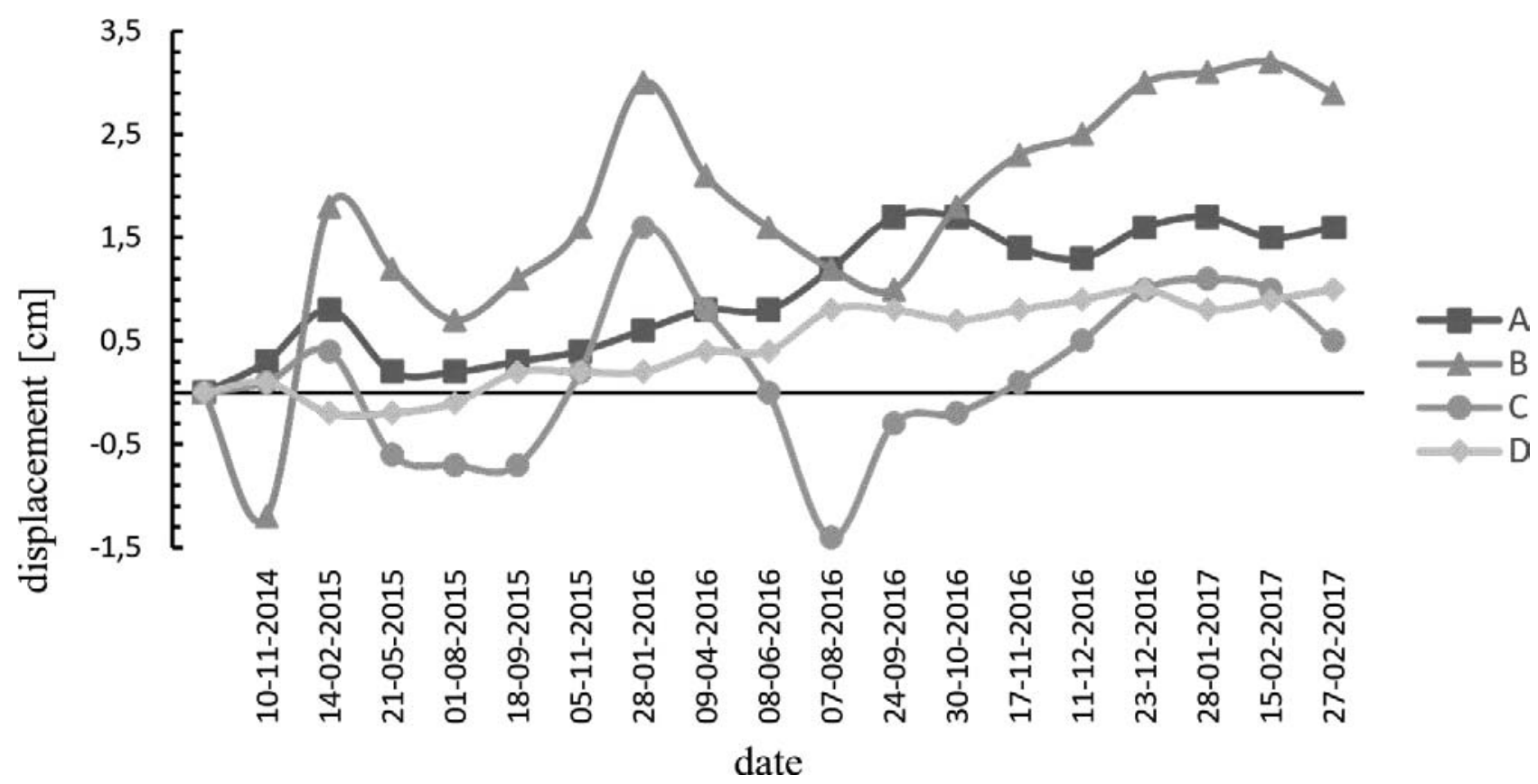

Fig. 7. Cumulative displacement in region the NAFZ or points: A, B, C and D from November 2014 to February 2017.

Recapping the results of the analysis, the northern part of the area compared to the southern part shows greater displacements. Visible branches on the generated maps are related to the fact that in Turkey there is a system of many faults dynamically connected together with NAF. In this way, the stresses that are released in the earth's crust are also able to spread more rapidly to vast areas. In the case of Turkey it should be emphasized that most of the manifestations of tectonic activity are due to collisions of lithosphere plates. Its part located south of the North Anatolian Fault and west of the East Anatolian Fault moves to west. Unlike some parts of Turkey outside of that zone, which is located on the Anatolian continental plate and moves west. This movement causes the pressure of the African plate that moves north. In addition, the Arabic plate also causes complications in contact with the Anatolian and Eurasian plates, creating a folding - faulting the Bitlis - Zagros zone in the eastern part of the country.

For in-depth analysis, it would be useful to use data from the North Anatolian Fault along the entire length of the radar interferometry. This would allow for a better understanding of the changes that are taking place in this area of the world.

\section{Conclusions}

This article presented the application of Synthetic Aperture Radar Interferometry SBAS to determine the displacements of a selected fragment of the terrain in the area of the North Anatolian Fault in Turkey. Measurements were made using specialized software GMT5SAR. Selection of the SBAS method was due to the fact that this technique is a characterized by the minimized influence of atmospheric artefacts and possible topographic errors. In addition, it allowed selections of both baseline and temporal distances, on the basis of which interferograms were generated between pairs of images. By defining these two parameters it was possible to eliminate spatial and temporal decorrelations. As a result of data processing, the SBInSAR method has been shown to be significantly effective in detecting displacements of the selected fault zone over a longer period of time - over 2 years.

In order to determine the displacements of the North Anatolian Fault, 73 satellite images of Sentinel 1 were used, which were processed using the SBAS method. Based on the obtained results, the tectonic activity of the studied area was analyzed. The cumulative displacements in the center of the fault range from -10 $\mathrm{cm}$ to $10 \mathrm{~cm}$. In addition, the movements of several points located in this area have been analyzed, whose displacements oscillate from $-1.5 \mathrm{~cm}$ to $3.5 \mathrm{~cm}$. The above results indicate the occurrence of the phenomenon of uplift and subsidence of the surface. The variations in altitude of the surface can be related to the geological processes responsible for significant seismic activity, referred to as the collision of lithosphere plates. It is precisely the continental plates that, through their movements, in the Earth's crust, cause considerable tension, often leading to earthquakes. The North Anatolian Fault as a geological boundary between the Anatolian plate and the Eurasian plate continually undergoes their influence, leading to its displacements.

Based on the conducted work, it has been proved that it is possible to obtain high accuracy of results and information on changes in topography of the area for the studied area by applying the SBInSAR method. This technology is characterized by the availability of both input materials and the required software, but requires good hardware with high computing power. Final products can be processed in any way according to user requirements. Their digital form provides the opportunity to return at any time to the various stages of 
work. The SBAS method allows detecting displacement of various types of land (faults, volcanoes, slides) and the accuracy of results can be increased by combining it with other methods such as GPS or PSInSAR.

\section{References}

1. P. Berardino, G. Fornaro, R. Lanari, E. Sansosti, IEEE Transactions on Geoscience and Remote Sensing, 40, 2375 - 2383 (2002)

2. R. Lanari, F. Casu, M. Manzo, G. Zeni, P. Berardino, M. Manunta, A. Pepe, Pure and Applied Geophysics, 164, 637-661 (2007)

3. P. Shanker, F. Casu, H.A. Zebker, R. Lanari, IEEE Transactions on Geoscience and Remote Sensing, 8, 592-596 (2011)

4. C. Zhao, Q. Zhang, C.Yang, J. Zhang, W. Zhu, F. $\mathrm{Qu}, \mathrm{Y}$. Liu, International Association of Hydrological Sciences, 372, 305-309 (2015)

5. F. Chen, H. Lin, Z. Li, Q. Chen, J. Zhou, Remote Sensing of Environment, 123, 532-540 (2012)

6. Y. Cheng-sheng, Z. Qin, Z. Chao-ying, W. Qingliang, J. Ling-yun, Journal of Geodynamics, 75, 3440 (2014)

7. T.R. Laukens, J.Dehls, Y.Larsen, K.A. Høgda, D.J. Weydahl, Fringe Workshop (2006)

8. F. Calò, S. Abdikan, S. Görüm, A. Pepe, H. Kiliç, F.B. Şanli, Remote Sensing, 7, 16519-16536 (2015)

9. I. Ketin, Geologische Rundschau, 36, 77-83 (1948)

10. Z. Cakir, S. Ergintav, A.M. Akoğlu, R. Çakmak, O. Tatar, M. Meghraoui, Journal of Geophysical Research: Solid Earth, 119, 7934-7943 (2014)

11. A.E. Aksu, T.J. Calon, R.N. Hiscott, GSA Today (2000)

12. M. Bohnhoff, P. Matrinez-Garzón, F. Bulut, E. Stierle, Y. Ben-Zion, Tectonophysics, 674, 147-65 (2016)

13. J.L. Gross, L.T. Phan, U.S. Geological Survey, 1193, 64 (2000)

14. R. Gore, National Geographic Polska, (2015)

15. A.A. Özacar, G. Zandt, H. Gilbert, S.L. Beck, Geological Society, 340, 485-496 (2010)

16. B. Rabus, M. Eineder, A. Roth, R. Bamler, ISPRS Journal of Photogrammetry \& Remote Sensing, 57, 241-262 (2003)

17. https://scihub.copernicus.eu/dhus/\#/home (2017)

18. http://topex.ucsd.edu/gmtsar/demgen/ (2017)

19. M. Manzo, Y. Fialko, F. Casu, A. Pepe, R. Lanari, Pure and Applied Geophysics, 169, 1463-1482 (2011)

20. F. Casu, The Small BAseline Subset technique: performance assessment and new developments for surface deformation analysis of very extended areas (Dept. of Electrical and Electronic Engineering University of Cagliari, 2009)
21. T. Xiaopeng, D. Sandwell, InSAR workshop, Conference materials (2013)

22. F. Bulut, M. Bohnhoff, W.L. Ellsworth, M. Aktar, G. Dresen, USGS Staff - Published Research, 114, 16 (2009)

23. M. Bohnhoff, F. Bulut, G. Dresen, P.E. Malin, T. Eken, M. Aktar, Nature Communications, 4, 1999 (2013)

24. P. Berardino, F. Casu, G. Fornaro, R. Lanari, M. Manunta, M. Manzo, A. Pepe, E. Sansosti, Small Baseline DIFSAR Techniques for Earth Surface Deformation Analysis (2003) 